\title{
The relationship between four-wheel drives and risky driving behaviours
}

Abdulbari Bener ${ }^{1,2}$, Junaid A. Razzak ${ }^{3}$, David Crundall ${ }^{4}$, Katharine A. Allen ${ }^{5}$

${ }^{1}$ Departments of Medical Statistics and Epidemiology, Hamad Medical

Corporation and Department of

Public Health, Weill Cornell Medical College, Qatar, ${ }^{2}$ Evidence for

Population Health Unit, School of Epidemiology and Health Sciences,

The University of Manchester,

Manchester, ${ }^{4}$ Accident Research Unit, School of Psychology,

The University of Nottingham,

Nottingham, UK, ${ }^{3}$ Emergency

Medicine, Aga Khan University

Hospital, Karachi, Pakistan,

${ }^{5}$ International Injury Research

Unit, Johns Hopkins University

Bloomberg School of Public Health, Baltimore, MD 21205, USA

Address for the Correspondence: Prof. Abdulbari Bener,

Department of Medical Statistics and Epidemiology, Hamad Medical

Corporation and Department of Public Health, Weill Cornell Medical College, PO Box 3050,

Doha, Qatar.

E-mail: abener@hmc.org.qa

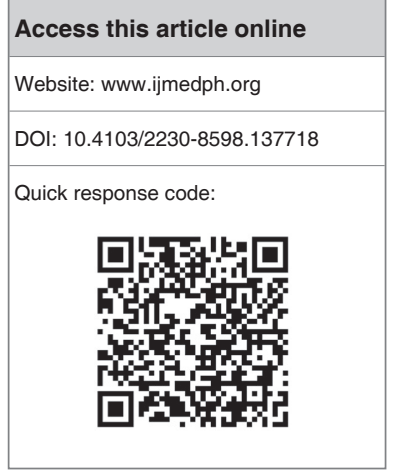

Background: Given the increased number of four wheel drive (4WD) vehicles in Qatar and their involvement in crashes, casualties and road fatalities, it is important to understand the association between risky driving behavior and 4WD crashes. Aim/Objective: This study aimed to determine the association between risky driving behaviours and 4WD vehicles and its impact on road traffic accidents in the State of Qatar. Materials and Methods: A cross sectional survey was conducted using a multistage stratified cluster sampling technique to recruit 1824 drivers of two wheel drive (small cars) and 4WD across different primary health centres (PHCs) in Qatar. The Driver Behaviour Questionnaire (DBO) and Driver Skill Inventory (DSI) were used to collect the data. Information regarding socio-demographic and road traffic crashes during last three years was also obtained. Multivariate logistic regression was used to analyse the data. Results: $762(41.8 \%)$ owned 4WD vehicles. Drivers of 4WD were significantly higher between $30-50$ years age $(P<0.001)$, urban dwellers $(P=0.003)$, having more driving experience (atleast 5 years) $(P<0.001)$ and annual mileage higher than the drivers of small cars $(P<0.001)$. A significantly higher proportion of 4WD drivers had previous penalties for traffic violations such as crossing a red traffic signal $(51.6 \%$ vs. $21.4 \% ; P<0.001)$ or exceeding the speed limit $(35 \%$ vs. $27.8 \% ; P<0.001)$. A higher proportion of $4 W^{2} s^{\prime}$ drivers reported previous involvement in accidents as compared to the drivers of small cars $(42.4 \%$ vs. $35.7 \%$; $p$ 0.004). The risk of accident involvement was 1.21 times higher among drivers of 4WD as compared to the counterparts (OR 1.21; $95 \% \mathrm{Cl} ; 1.01-1.46)$. Besides, excessive speed, annual mileage, male gender, traffic violations, lapses, errors and driving skills were significantly associated with crashes. Conclusion: The drivers of 4 WD cars are at higher risk of crashes as compared to the drivers of small cars. Also, they have significantly more traffic violations, lapses, and errors. Future interventions and control measures should target the drivers of 4WD for better results.

Key words: Accident, driver behaviour questionnaire, four-wheel drive, Qatar, road traffic crashes, risk taking behaviour, speed, seat-belt usage, small car, traffic offence

\section{INTRODUCTION}

Road traffic injuries are a major cause of death and disability globally, with a disproportionate number occurring in developing countries. ${ }^{[1,2]}$ The size of this problem is only increasing in such countries due to the rapid motorization of the population and other risk factors such as individual driving behaviors like excessive speed and traffic violations. ${ }^{[2-7]}$ Currently in the Arab Gulf countries, which consists of the Kingdom of Saudi Arabia, Bahrain, the United Arab Emirates, Qatar, Yemen, Kuwait, and Oman, road traffic injuries (RTIs) are the second biggest killer and second only to cardiovascular diseases in terms of deaths. ${ }^{[12]}$

Traffic records indicate that certain vehicle types are over-represented in the number of crashes as compared to other vehicle types in Arab Gulf countries. For instance, it is reported that Four-Wheel Drives (4WDs) are associated with frequent crashes, severe casualties and fatalities and even increase the hazards of injury to small cars' drivers and pedestrians. ${ }^{[2,5,8]}$ In the State of Qatar, the popularity of $4 \mathrm{WD}$ s has increased significantly over the last ten years and a 2008 study showed that $40.3 \%$ of all drivers involved in a car crash were using a 4WD. ${ }^{[6]}$ 
While 4WD seem to be very stable and strong, unfortunately they are associated with frequent crashes, severe casualties and fatalities. ${ }^{[2,5,9,10]}$ More recently, a study examined the vehicular damage resulting from motor vehicle crashes involving 4WD vehicles and small cars in the State of Oklahoma in the United States. ${ }^{[3]}$ The results indicated that small cars sustain significantly greater vehicular damage than 4WDs. The impact of 4WD vehicles on crashes and injuries along with the behavioural factors related to the crash involvement of 4WD vehicles are controversial and still remain unexamined in most developing and developed countries.

Given the increased number of 4WD vehicles present on Qatari roads and their level of involvement in crashes, casualties and road fatalities, it is increasingly important to understand the factors contributing to $4 \mathrm{WD}$ crashes. There is a common understanding among researchers that individual differences play a role in driving performance. ${ }^{[5-7]}$ While 4WDs and small cars often differ in their performance characteristics, there are also differences in driver-vehicle interactions, which go beyond performance characteristics and relate more to social, habits and personal perceptions. Considering the escalating number of 4WD vehicles on Qatari roads and the relative paucity of data on the effects of 4WDs on road traffic crashes, this current study was conducted to contribute to the small but growing body of literature on the impact of $4 \mathrm{WDs}$ on driver behaviours, crash involvement and associated risk factors as compared to small cars among drivers in Qatar. ${ }^{[2,5-7,11]}$ The results of this study have important implications for prevention and control of road traffic accidents by developing policies and advocacy to correct risky driving behaviours among Qatari drivers particularly those owning 4WD cars.

The aim of the present study was to examine the impact of 4WD vehicles on risky driver behaviours and road traffic accidents in the State of Qatar.

\section{MATERIALS AND METHODS}

\section{Participants}

A multistage stratified cluster sampling was applied by using the administrative division of Qatar into twenty-one (21) Primary Health Care (PHC) Clinics. PHCs are approximately equally-sized in terms of number of inhabitants. The participants were selected among patients attending eleven (11) PHC Centres (8 urban and 3 semiurban), which represent over $70 \%$ of total visits per year. Qualified nurses and health educators were recruited in the study and trained for one week by the Principal Investigator to collect data using the structured questionnaire from the randomly selected Qatari men and women visiting the respective PHCs during the period from January 2012 to September 2012.

A cross-sectional survey was conducted. In order to ensure a representative sample of the study population, the sampling plan was stratified with proportional allocation according to stratum size. Stratification was based upon geographical location. With a $2.5 \%$ error bound and 99\% confidence limit the required sample size was estimated as 2,400 drivers. The participants were sampled from each region so that the sample size in each region was proportional to its share of total population in Qatar. A health educator and social workers recorded the data of each subject on a standardized questionnaire. A representative sample of 2,400 drivers was selected and approached. The sample included males and females aged 18 years and older. Out of total 2400 drivers, 1824 drivers participated in this survey giving a response rate of $76 \%$.

\section{Pilot study}

A pilot study was conducted among 100 participants selected from the PHCs before the initiation of main survey. Based on the results of the pilot study necessary corrections and modifications were made in the questionnaire.

\section{Questionnaire}

The questionnaire used for data collection was composed of multiple sections including socio-demographic information such as age, gender, marital status, educational level, occupation, place of living, housing conditions, and information on driving experience, type of car, frequency of seatbelt use and reasons for not wearing a seat belt, speed choice on different roads, traffic offences and history of accident during last 3 years. In addition, data related to driving behavior and skills were also collected using the Driver behaviour Questionnaire (DBQ) and Driver Skill Inventory (DSI).

Vehicles were divided into two groups such as four wheel drive cars (4WD) vs. two wheel drive (small cars). The term 4WD refers to an automobile with a drive train that allows all four wheels to receive torque from the engine simultaneously while on the other hand the small cars refer to an automobile with drive train that allows only two wheels (rear-wheel or front-wheel) to receive torque from the engine simultaneously.

\section{Aberrant Driver Behaviours}

The Manchester Driver Behaviour Questionnaire (DBQ) is one of the most widely used instruments in Traffic Psychology for measuring self-reported driving style and investigating the relationship between driving behaviour and accident involvement. ${ }^{[12-19]}$ The DBQ with extended violations was used to measure aberrant driver behaviours. ${ }^{[18-20]}$ An Arabic version of the DBQ was revised by a bilingual co-investigator and back translated by another bilingual expert. $^{[21]}$ The translators then made the necessary corrections, modifications and rewording after considering any minor differences and discrepancies.

The extended version of the DBQ includes aggressive and ordinary violations (10 items, e.g. "disregard speed limit on motorways"), lapses (8 items, e.g. "Forget where you left your car in the car park", and errors (8 items, e.g. "misjudging the speed of another vehicle when overtaking"). Two violations items were dropped because of cultural or structural factors (e.g., drinking and driving, and "pulling out of, force your way"). Gras and colleagues ${ }^{[22]}$ also suggested that "pulling out of, force your way" item might be omitted from future research 
because of its instability across the DBQ factors. Two violations items were also revised after receiving feedback from drivers. "Disregard speed limits on a residential road" was revised as "Disregard the speed limits late at night or early in the morning". "Drive close to the car in front, making it difficult to stop in an emergency" was revised as "Drive especially close to the car in front as a signal to its driver to go faster or get out of the way". Participants were asked to indicate how often they committed each of the 26 behaviours in the previous year on a six-point scale $(0=$ never, $1=$ hardly ever, $2=$ occasionally, $3=$ quite often, $4=$ frequently and $5=$ nearly all the time).

\section{Driver Skill Inventory (DSI)}

The Driver Skill Inventory (DSI) is a 20 item self-reported measure of perceptual-motor (10 items, e.g. controlling the vehicle) and safety skills (10 items) developed by Lajunen and Summala. ${ }^{[13]}$ The DSI was previously translated into English and has been shown to have good reliability and predictive validity in diverse Western cultures. ${ }^{[23]}$ Similar to the DBQ translation, a translated Arabic version of the DSI was revised by a bilingual co-investigator and back translated again by second bilingual expert. Both translators met and made necessary corrections, modifications and word corrections after considering the minor translation differences and discrepancies. This instrument asked drivers to rate how weak or strong they were on the given skills by using a 5 -point scale $(0=$ very weak and $4=$ very strong).

\section{Statistical analysis}

Analysis was performed using the Statistical Package for Social Sciences [SPSS- Version \# 20]. The Student-t test was used to ascertain the significance of differences between mean values of two continuous variables and confirmed by a non-parametric Mann-Whitney test. The Chi-square and Fisher's exact tests (twotailed) were performed to test for differences in proportions of categorical variables between two or more groups. Cronbach's alpha reliability coefficients were also calculated for assessing the internal consistency of the DBQ scale scores. Multivariate logistic regression was performed with accident involvement as dependent and four DBQ factors as independent variables. Age, sex, and annual mileage were forced into the model to control their effect. The Pearson's correlation coefficient was used to evaluate the strength association between two continuous variables. The level $P<0.05$ was considered as the cut-off value for significance.

\section{RESULTS}

Out of a total 2400 only 1824 drivers (1362 male and 462 female) participated in this survey giving a response rate of $76 \%$. Only 762 drivers (41.8\%) owned 4WD while the remaining 1062 (58.2\%) owned small cars. The revealed that a statistically significant difference was present between drivers of 4WD and smalls cars in terms of age $(P<0.001)$, gender $(P<0.001)$ education $(P<0.001)$, occupation $(P=0.046)$, place of living $(P=0.003)$, driving experience $(P<0.001)$ and annual mileage (4WD $22437.6 \pm 776.6$ vs small car $(20,998.7 \pm 644.4)(P<0.001)$ [Table 1].
Table 2 gives risky behaviors and indicators by vehicle type. Less than half of the 4WD drivers (41.1\%) and $35.6 \%$ of small car drivers reported not wearing seatbelts. A significantly higher proportion of small car drivers as compared to 4WD drivers reported discomfort as the main reason for not wearing seatbelts ( 46.3 vs. $30 \% ; P<0.001$ ) while more than a quarter of the drivers of both 4WD and small cars reported a fear of being trapped in their vehicle as the main reason for not wearing a seatbelt. A significantly higher proportion of 4WD drivers as compared to small car drivers had previous penalties for traffic violations such as crossing a red traffic signal (51.6 vs. $21.4 \% ; P<0.001)$

\begin{tabular}{|c|c|c|c|}
\hline Variables & $\begin{array}{c}\text { 4WD } n=762 \\
n(\%)\end{array}$ & $\begin{array}{c}\text { Small car } n=1062 \\
n(\%)\end{array}$ & $P$ value \\
\hline Age (Mean \pm SD) & $36.6 \pm 9.9$ & $36.4 \pm 10.4$ & 0.778 \\
\hline \multicolumn{4}{|l|}{ Age Group } \\
\hline$<30$ & $223(29.3)$ & $352(33.1)$ & \\
\hline $30-39$ & $303(39.7)$ & $359(33.8)$ & $<0.001^{*}$ \\
\hline $40-49$ & $186(24.4)$ & $229(21.6)$ & \\
\hline$\geq 50$ & $50(6.6)$ & $122(11.5)$ & \\
\hline \multicolumn{4}{|l|}{ Gender } \\
\hline Male & $586(76.9)$ & $776(73.1)$ & 0.063 \\
\hline Female & $176(23.1)$ & $286(26.9)$ & \\
\hline \multicolumn{4}{|l|}{ Marital status } \\
\hline Single & $126(16.5)$ & $196(18.5)$ & \\
\hline Married & $614(80.6)$ & $820(77.2)$ & 0.132 \\
\hline Divorced/widowed & $22(2.9)$ & $46(4.3)$ & \\
\hline \multicolumn{4}{|l|}{ Education } \\
\hline Illiterate & $103(13.5)$ & $63(5.9)$ & \\
\hline Primary & $125(16.4)$ & $187(17.6)$ & $<0.001^{*}$ \\
\hline Intermediate & $122(16.0)$ & $162(15.3)$ & \\
\hline Secondary & $205(26.9)$ & $335(31.5)$ & \\
\hline University & $207(27.2)$ & $315(29.7)$ & \\
\hline \multicolumn{4}{|l|}{ Occupation } \\
\hline Not working/student & $84(11.0)$ & $104(9.8)$ & \\
\hline Housewife & $51(6.7)$ & $94(8.9)$ & $0.046^{*}$ \\
\hline Professional/sedentary & $475(62.3)$ & $695(65.4)$ & \\
\hline Manual & $152(19.9)$ & $169(15.9)$ & \\
\hline \multicolumn{4}{|l|}{ Place of living } \\
\hline Urban & $567(74.4)$ & $723(68.1)$ & $0.003^{*}$ \\
\hline Semi-urban & $195(25.6)$ & 339 (31.9) & \\
\hline \multicolumn{4}{|l|}{ Housing conditions } \\
\hline Flat & $301(39.5)$ & $422(39.7)$ & \\
\hline Villa & $305(40.0)$ & $384(36.2)$ & 0.113 \\
\hline Popular house & $156(20.5)$ & $256(24.1)$ & \\
\hline \multicolumn{4}{|l|}{ Driving experience } \\
\hline$<2$ year & 88 (11.5) & $154(14.5)$ & \\
\hline $2-5$ years & $166(21.8)$ & $311(29.3)$ & $<0.001^{*}$ \\
\hline $5-10$ years & $187(24.5)$ & $213(20.1)$ & \\
\hline$>10$ years & $321(42.1)$ & $384(36.2)$ & \\
\hline \multicolumn{4}{|l|}{ Annual mileage } \\
\hline Mean & 22437.6 & 20998.7 & $<0.001^{*}$ \\
\hline Standard deviation & 776.6 & 644.4 & \\
\hline
\end{tabular}

*Statistically significant difference based on $5 \%$ level of significance 
and exceeding the speed limit (35\% vs. $27.8 \%$; $P<0.001)$. Also, more than one third of the drivers of both 4WD and small cars reported the use of mobile phones while driving (40.4 vs. $43.5 \%$ ). A significantly higher proportion of 4WD drivers as compared to small cars reported excessive speeding (39.8 vs. $33.4 \% ; P=0.005)$ on a usual basis and traffic violation ( 35.4 vs. $30.8 \% ; P=0.048)$. In addition, a higher proportion of $4 \mathrm{WD}$ drivers reported previous involvement in vehicular crashes as compared to drivers of small cars (42 vs. $35.7 \% ; P=0.004$ ) [Table 2].

4WD drivers had a significantly higher mean score on all the DBQ violation questions as compared to the drivers of small cars. The mean scores of all errors were higher in drivers of 4WD than small cars except for "applying sudden brakes on a slippery road" where the mean score was similar between drivers of 4WD and small cars. The mean score was significantly higher for three errors "queuing to turn right on to a main road and hit the car at the front" $(1.54 \pm 1.90$ vs. $1.31 \pm 1.54 ; P=0.005)$, "Fail to check your rear-view mirror before changing lanes $(1.38 \pm 1.43$ vs. $1.20 \pm$ $1.31 ; P=0.004)$ and "underestimate the speed of an oncoming vehicle when overtaking $(1.48 \pm 1.44$ vs. $1.25 \pm 1.39 ; P=0.001)$ Also, drivers of 4WD had a higher mean lapses score as compared to small cars' drivers [Table 3].

\begin{tabular}{|c|c|c|c|}
\hline Variables & $\begin{array}{c}\text { 4WD } n=762 \\
n(\%)\end{array}$ & $\begin{array}{l}\text { Small car } \\
n=1062 n(\%)\end{array}$ & $P$ value \\
\hline \multicolumn{4}{|l|}{ Use of Seatbelt } \\
\hline Never & $313(41.1)$ & $378(35.6)$ & 0.097 \\
\hline Less than half of the trips & $103(13.5)$ & $167(15.7)$ & \\
\hline More than half of the trips & $221(29.0)$ & $320(30.1)$ & \\
\hline Always & $125(16.4)$ & $197(18.5)$ & \\
\hline \multicolumn{4}{|l|}{ Reason for not wearing seatbelt** } \\
\hline Discomfort & $233(30.6)$ & $492(46.3)$ & $<0.001^{*}$ \\
\hline Inconvenience & $199(26.1)$ & $388(36.5)$ & $<0.001^{*}$ \\
\hline Fear of being trapped & $227(29.8)$ & $310(29.2)$ & 0.782 \\
\hline \multicolumn{4}{|l|}{ Penalties due to traffic violation* } \\
\hline Crossing red traffic light & $393(51.6)$ & $227(21.4)$ & $<0.001^{*}$ \\
\hline Parking in forbidden places & $268(35.2)$ & $350(33.0)$ & 0.325 \\
\hline Exceeding speed limit & $267(35.0)$ & $295(27.8)$ & $<0.001^{*}$ \\
\hline \multicolumn{4}{|l|}{ Speed (Usual in km/hr)* } \\
\hline On $60 \mathrm{~km} / \mathrm{hr}$ road & $312(40.9)$ & $537(50.6)$ & $<0.001^{*}$ \\
\hline On $80 \mathrm{~km} / \mathrm{hr}$ road & $380(49.9)$ & $669(63.0)$ & $<0.001^{*}$ \\
\hline On $100 \mathrm{~km} / \mathrm{hr}$ road & $371(48.7)$ & $634(59.7)$ & $<0.001^{*}$ \\
\hline On $120 \mathrm{~km} / \mathrm{hr}$ road & $248(32.5)$ & $372(35.0)$ & 0.270 \\
\hline \multicolumn{4}{|l|}{ Usual behaviour during driving* } \\
\hline Using mobile phone & $308(40.4)$ & $462(43.5)$ & 0.189 \\
\hline Careless driving & $277(36.4)$ & $364(34.3)$ & 0.360 \\
\hline Excessive speeding & $303(39.8)$ & $355(33.4)$ & $0.005^{*}$ \\
\hline Alcohol \& drugs & $67(8.8)$ & $89(8.4)$ & 0.756 \\
\hline Traffic violation & $269(35.4)$ & $327(30.8)$ & $0.048^{*}$ \\
\hline \multicolumn{4}{|l|}{ Previous involvement in accident } \\
\hline Yes & $323(42.4)$ & $379(35.7)$ & $0.004^{*}$ \\
\hline No & $439(57.6)$ & $683(64.3)$ & \\
\hline
\end{tabular}

**Only positive responses shown, number and percentages may not add up to total, *Statistically significant difference based on $5 \%$ level of significance
Overall the mean driving skills score was similar between the drivers of 4WD and small cars (40.01 \pm 9.61 vs. $40.26 \pm 9.79)$. The mean score on "making a hill start on a steep incline" was higher for 4WD drivers as compared to small cars $(P=0.007)$ while the mean score was higher on "avoiding competition in traffic" for the drivers of small cars as compared to 4WD ( $\mathrm{p}=0.016)$. Reverse parking in a narrow gap had a significantly higher mean score in 4WD drivers $(2.07 \pm 1.34)$ than small cars $(1.84 \pm 1.32)$ [Table 4].

Multivariate logistic regression revealed that violations, errors, lapses, driving skills, , mileage, being male, and owning a 4WD are significantly associated with previous involvement in accidents, after adjusting for age and driving experience. While excessive speed (OR 2.65 95\% CI 1.53 - 4.78); mileage (OR 2.32, 95\% CI 1.79-3.58), violations (OR 1.40, 95\% CI 1.16-1.69), errors (OR 1.24, 95\% CI 1.10-1.49, lapses (OR 1.27, 95\% CI ; 1.10-1.53), being male (OR $1.71,95 \%$ CI; 1.38-2.12), and owning a 4WD (OR 1.21, 95\% CI; 1.01-.46) significantly increased the odds of accident involvement, a higher score on the driving skills questionnaire significantly decreased the odds of previous involvement in accidents (OR 0.71, 95\% CI 0.59-0.85) [Table 5].

\section{DISCUSSION}

The popularity of 4WD has increased significantly over the last ten years in the State of Qatar. ${ }^{[2,6]}$ With the escalating number of 4WD vehicles present on Qatari roads, it is becoming increasingly important to understand the factors contributing to 4WD crashes and injuries. While 4WD and other cars often differ in their performance characteristics, it is also possible that there are differences in drivervehicle interactions, which go beyond performance characteristics and relate more to social, habits and personal perceptions.

In this study, the data on drivers of 4WD and small cars and their risky driving behaviors were analyzed to examine the relationship between 4WDs and risky driving behavior. Vehicle rollover is the most common characteristic of 4WD crashes. Among all fatal crashes in Qatar, a significantly higher proportion of 4WD vehicles were involved in road traffic accidents compared with passenger cars (Table 2, $42.4 \%$ versus $35.7 \% P=0.004$ respectively). The current study is anticipated that this will provide further insight and guidance to inform the development and implementation of strategies designed to reduce the frequency and severity of 4WD crashes. 4WD are becoming increasingly popular recreational devices and our study showed that significantly higher proportion of Qatari population between 30-49 years of age were 4WD users. This is significant given that road traffic injuries are the second most common cause of death across all age groups in the State of Qatar, ${ }^{[6,7]}$ in the United Arab Emirates ${ }^{[5,24]}$ and in Saudi Arabia. ${ }^{[25]}$

This study shows that $42.4 \%$ of $4 \mathrm{WD}$ drivers reported previous involvement in a road traffic crash. This is consistent with the previous reported in Qatar, ${ }^{[6,7]}$ in the United Arab Emirates ${ }^{[5,24]}$ and in Saudi Arabia. ${ }^{[25]}$ Studies have found that 4WD vehicles are aggressive in crashes, creating a high chance of serious injury to other small car 


\begin{tabular}{|c|c|c|c|}
\hline Variables & 4WD $n=762$ & Small car $n=1062$ & $P$ value \\
\hline \multicolumn{4}{|l|}{ Violations } \\
\hline Drive especially close to the car in front as a signal to its driver to go faster or get out of the way & $1.61 \pm 1.60$ & $1.29 \pm 1.49$ & $<0.001^{*}$ \\
\hline Cross a junction knowing that the traffic lights have already turned red & $1.26 \pm 1.54$ & $1.03 \pm 1.44$ & $0.001^{*}$ \\
\hline Disregard the speed limits late at night or early in the morning & $1.78 \pm 1.69$ & $1.51 \pm 1.61$ & $0.001^{*}$ \\
\hline Disregard the speed limits on a motorway & $1.59 \pm 1.65$ & $1.31 \pm 1.52$ & $<0.001^{*}$ \\
\hline $\begin{array}{l}\text { Have an aversion to a particular class of road user and indicate your hostility by whatever } \\
\text { means you can }\end{array}$ & $1.42 \pm 1.49$ & $1.13 \pm 1.37$ & $<0.001^{*}$ \\
\hline Become impatient with a slow driver in the outer lane and overtake on the inside(right) lane & $1.99 \pm 1.73$ & $1.77 \pm 1.67$ & $0.007^{*}$ \\
\hline Get involved with unofficial 'races' with other drivers & $1.47 \pm 1.60$ & $1.33 \pm 1.58$ & 0.060 \\
\hline $\begin{array}{l}\text { Angered by another driver's behaviour, you give chase with the intention of giving him/her a } \\
\text { piece of your mind }\end{array}$ & $1.60 \pm 1.53$ & $1.26 \pm 1.44$ & $<0.001^{*}$ \\
\hline Sound your horn to indicate your annoyance to another driver & $2.06 \pm 1.60$ & $1.73 \pm 1.54$ & $<0.001^{*}$ \\
\hline $\begin{array}{l}\text { Stay in a motorway that you know will be closed ahead until the last minute before forcing } \\
\text { you way into the other lane }\end{array}$ & $1.41 \pm 1.44$ & $1.23 \pm 1.47$ & $0.010^{*}$ \\
\hline \multicolumn{4}{|l|}{ Errors } \\
\hline Attempt to overtake someone that you hadn't noticed to be signalling a left turn & $1.24 \pm 1.47$ & $1.18 \pm 1.49$ & 0.393 \\
\hline Miss 'Give Way' signs and narrowly avoid colliding with traffic having right of way & $1.26 \pm 1.46$ & $1.16 \pm 1.45$ & 0.147 \\
\hline Fail to notice that pedestrians are crossing when turning into a side street from a main road & $1.23 \pm 1.37$ & $1.15 \pm 1.42$ & 0.232 \\
\hline $\begin{array}{l}\text { Queuing to turn right onto a main road, you pay such close attention to the mainstream of } \\
\text { traffic that you nearly hit the car in front }\end{array}$ & $1.54 \pm 1.90$ & $1.31 \pm 1.54$ & $0.005^{*}$ \\
\hline On turning right nearly hit a two wheeler who has come up on your inside & $1.39 \pm 1.47$ & $1.27 \pm 1.49$ & 0.117 \\
\hline Fail to check your rear-view mirror before pulling out or changing lanes, etc & $1.38 \pm 1.43$ & $1.20 \pm 1.31$ & $0.004^{*}$ \\
\hline Under estimate the speed of an oncoming vehicle when overtaking & $1.48 \pm 1.44$ & $1.25 \pm 1.39$ & $0.001^{*}$ \\
\hline Apply sudden brakes on a slippery road, or steer wrong way in a skid & $1.25 \pm 1.29$ & $1.24 \pm 1.27$ & 0.855 \\
\hline \multicolumn{4}{|l|}{ Lapses } \\
\hline Get into the wrong lane when approaching a roundabout or a junction & $1.02 \pm 1.38$ & $0.94 \pm 1.23$ & 0.182 \\
\hline Misread the signs and exit from the roundabout on the wrong road & $1.33 \pm 1.67$ & $1.20 \pm 1.55$ & 0.075 \\
\hline Forget where you left your car in the car park & $1.19 \pm 1.33$ & $1.03 \pm 1.22$ & $0.010^{*}$ \\
\hline Hit something when reversing that you had not previously seen & $1.44 \pm 1.38$ & $1.32 \pm 1.28$ & 0.061 \\
\hline Attempt to drive away from the traffic lights & $1.49 \pm 1.41$ & $1.35 \pm 1.40$ & $0.034^{*}$ \\
\hline $\begin{array}{l}\text { Switch on one thing, such as headlights, when you meant to switch on something else, } \\
\text { such as wipers }\end{array}$ & $1.57 \pm 1.94$ & $1.53 \pm 2.08$ & 0.711 \\
\hline $\begin{array}{l}\text { Intending to drive to destination A and, you 'wake up' to find yourself in destination B, } \\
\text { because the latter is your more usual destination }\end{array}$ & $1.36 \pm 1.41$ & $1.14 \pm 1.32$ & $0.001^{*}$ \\
\hline Realise you have no clear recollection of the road along which you have been travelling & $1.36 \pm 1.51$ & $1.19 \pm 1.43$ & $0.015^{*}$ \\
\hline
\end{tabular}

occupants or unprotected road users into which they crash. They are relatively unstable vehicles, with a high risk of rollover which is a very serious crash in terms of potential for serious fatal injury. Although a larger proportion of drivers included in this sample had small cars, drivers of 4WDs were more significantly associated with being involved in a previous road traffic crash. Additionally, a significantly higher proportion of $4 \mathrm{WD}$ drivers as compared to small car drivers had previous penalties for traffic violations such as crossing a red traffic signal and exceeding the speed limit. 4WD drivers also had a significantly higher mean score on all the DBQ violation questions. Such findings are consistent with the existing DBQ literature, which shows that violations were associated with higher number of accidents and penalties. ${ }^{[16,26,27]} \mathrm{A}$ recent study showed that lapses and errors were related to accident involvement in United Arab Emirates and Qatar as much as violations. ${ }^{[7]}$ As indicated by this study's findings, it appears that 4WD drive more dangerously and carelessly than small cars. These results fall inline with a 2008 study on 4WDs in Qatar, ${ }^{[6]}$ which confirms that errors and lapses are of critical importance and do make a difference in traffic safety in Qatar. It is hypothesized that this might be due to cultural or education factors, especially since previous studies have illustrated that the knowledge of rules and the meaning of traffic signs in Arab countries vary considerable when compared to highincome developed countries like the European, Australia and other Western Countries. ${ }^{[15,28,29]}$

Multivariable regression analysis in this study revealed that apart from violations, errors, lapses, driving skills, and owning a 4WD, being a male was also significantly associated with previous involvement in road traffic accident. This finding is consistent with previous studies reporting male gender at higher risk for traffic crashes. ${ }^{[14,28-30]}$

These findings contribute to a small but growing literature on road traffic injuries in the State of Qatar and suggest that 4WDs have a considerable impact on crashed and road traffic injuries. The magnitude of motor vehicle injuries from 4WD vehicles is a growing 


\begin{tabular}{|c|c|c|c|c|}
\hline Variables & Total $N=1824$ Mean \pm SD & 4WD $n=762$ & Small car $n=1062$ & $P$ value \\
\hline Driving Skills ( Mean \pm SD) & $40.16 \pm 9.7$ & $40.01 \pm 9.61$ & $40.26 \pm 9.79$ & 0.584 \\
\hline Performance in critical situation & $2.31 \pm 1.30$ & $2.34 \pm 1.32$ & $2.30 \pm 1.28$ & 0.507 \\
\hline Driving behind a slow car without getting impatient & $1.82 \pm 1.35$ & $1.76 \pm 1.37$ & $1.86 \pm 1.33$ & 0.122 \\
\hline Managing the car through a skid & $2.20 \pm 1.38$ & $2.17 \pm 1.41$ & $2.23 \pm 1.36$ & 0.307 \\
\hline Predicting traffic situations ahead & $1.88 \pm 1.36$ & $1.87 \pm 1.37$ & $1.88 \pm 1.35$ & 0.855 \\
\hline Driving carefully & $2.06 \pm 1.39$ & $2.01 \pm 1.38$ & $2.09 \pm 1.40$ & 0.239 \\
\hline Knowing how to act in particular traffic situation & $2.16 \pm 1.49$ & $2.14 \pm 1.44$ & $2.17 \pm 1.42$ & 0.565 \\
\hline lane-changing in heavy traffic & $1.94 \pm 1.35$ & $1.99 \pm 1.36$ & $1.91 \pm 1.34$ & 0.201 \\
\hline Fast reactions & $2.05 \pm 1.37$ & $2.06 \pm 1.39$ & $2.04 \pm 1.37$ & 0.790 \\
\hline Showing consideration for other road users & $1.83 \pm 1.35$ & $1.77 \pm 1.35$ & $1.87 \pm 1.35$ & 0.119 \\
\hline Stay calm in irritating situations & $1.89 \pm 1.31$ & $1.88 \pm 1.31$ & $1.90 \pm 1.31$ & 0.800 \\
\hline Controlling the vehicle & $2.19 \pm 1.32$ & $2.14 \pm 1.31$ & $2.22 \pm 1.33$ & 0.198 \\
\hline Avoid competing in traffic & $1.92 \pm 1.42$ & $1.83 \pm 1.45$ & $1.99 \pm 1.40$ & $0.016^{*}$ \\
\hline Keeping a sufficient following distance & $1.88 \pm 1.27$ & $1.82 \pm 1.29$ & $1.93 \pm 1.26$ & 0.090 \\
\hline Make a hill start on a steep incline & $1.95 \pm 1.32$ & $2.05 \pm 1.36$ & $1.88 \pm 1.29$ & $0.007^{*}$ \\
\hline Overtaking & $2.19 \pm 1.23$ & $2.23 \pm 1.22$ & $2.15 \pm 1.24$ & 0.163 \\
\hline Relinquishing legitimate right when necessary & $2.00 \pm 1.34$ & $2.02 \pm 1.36$ & $1.99 \pm 1.33$ & 0.605 \\
\hline Controlling to the speed limits & $1.85 \pm 1.36$ & $1.84 \pm 1.32$ & $1.85 \pm 1.39$ & 0.875 \\
\hline Avoid unnecessary risks & $2.15 \pm 1.24$ & $2.09 \pm 1.27$ & $2.20 \pm 1.22$ & 0.072 \\
\hline Tolerating other drivers errors calmly & $1.96 \pm 1.31$ & $1.93 \pm 1.32$ & $1.97 \pm 1.31$ & 0.522 \\
\hline Reverse parking in a narrow gap & $1.93 \pm 1.34$ & $2.07 \pm 1.34$ & $1.84 \pm 1.32$ & $0.001^{*}$ \\
\hline
\end{tabular}

Two sided $P$ values based on independent sample $t$ test. Score range $0-4,{ }^{*}$ Statistically significant difference based on $5 \%$ level of significance

\begin{tabular}{|c|c|c|c|}
\hline \multicolumn{4}{|c|}{$\begin{array}{l}\text { Table 5: Multivariate Logistic regression analyses } \\
\text { of accident involvement as a function of aberrant } \\
\text { driver behaviour and type of vehicle owned } \\
(N=1,824)\end{array}$} \\
\hline Variables & Odds ratio & $\begin{array}{c}95 \% \text { Confidence } \\
\text { Interval }\end{array}$ & $P$ value \\
\hline Excessive speed & 2.65 & $1.53-4.78$ & $<0.001^{*}$ \\
\hline Mileage (km) & 2.32 & $1.79-3.58$ & $<0.001^{*}$ \\
\hline Gender (Male) & 1.71 & $1.38-2.12$ & $<0.001^{*}$ \\
\hline Violations & 1.40 & $1.16-1.69$ & $<0.001^{*}$ \\
\hline Lapses & 1.27 & $1.10-1.53$ & $0.010^{*}$ \\
\hline Errors & 1.24 & $1.10-1.49$ & $0.026^{*}$ \\
\hline \multicolumn{4}{|c|}{ Type of vehicle owned: } \\
\hline $4 W D$ & 1.21 & $1.01-1.46$ & \\
\hline Small car & 1 & 1 & $0.045^{*}$ \\
\hline Driving skills & 0.71 & $0.59-0.85$ & $<0.001^{*}$ \\
\hline
\end{tabular}

Note: Models adjusted for age, years of driving experience. Outcome variable ( 1 = previous accident, $0=$ No accident), *Statistically significant difference based on $5 \%$ level of significance

problem and requires urgent attention. Appropriate prevention is essential and will require close inter-sectoral collaboration between, traffic police, health, law, and transport authorities. Developing a research strategy for prevention will reduce casualties and death on the road in order to solve this major public health problem. A romantic vision offered by 4WD vehicles of outdoor adventures, toughness and safety. The appeal of 4WDs has extended to urban dwellers. Many 4WDs never go "off-road" but their owners enjoy the high seating position and feeling of safety that these vehicles provide for urban driving. The market for 4WDs is growing at double the rate of car sales in general. The best measure of prevention that government may decrease the amount of importing 4WD into country.
There are a number of limitations in the methodology used for this study mainly due to practical limitations. As mentioned earlier, this study is a cross sectional study and conducted at the PHC Centers. Another limitation was the vehicle type; we limit the experiment to one vehicle of each type. The geographic location of PHC Centre in which the study was conducted is another limitation, although, $11 \mathrm{PHC}$ represent over $70 \%$ of the inhabitant population. It is also expected that the responses for the violations, errors, lapses, and driving skills are likely to be correlated for the same individuals. Consequently, the estimates from such models would tend to be inefficient (inflated standard errors) by not capturing this correlation and this could be further considered limitation. The strength of this study based on a large sample size and representative sample of participated have giving a response rate of $76 \%$.

\section{CONCLUSION}

The drivers of 4WD cars are at higher risk of crashes as compared to the drivers of small cars. Also, they have significantly more traffic violations, lapses, and errors. Future interventions and control measures should target the drivers of 4WD for better results. Appropriate prevention strategies should include inter-sectoral collaboration between traffic police, health, law, and transport authorities.

\section{ACKNOWLEDGEMENT}

This work was generously supported and funded by the Qatar Foundation Grant No. UREP 11-100-3-020. The authors would like to thank the Hamad Medical Corporation for their support and ethical approval (HMC RP \# 12060/12). 


\section{REFERENCES}

1. Murray CJ, Lopez AD. Alternative projections of mortality and disability by cause 1990-2020: Global burden of disease study. Lancet 1997;349: 1498-504.

2. Bener $A$. The neglected epidemic: Road traffic accidents in a developing country, State of Qatar. Int J Inj Contr Saf Promot 2005;12:45-7.

3. Broyles RW, Clarke SR, Narine L, Baker DR. Factors contributing to the amount of vehicular damage resulting from collisions between four-wheel drive vehicles and passenger cars. Accid Anal Prev 2001;33:673-8.

4. Broyles RW, Narine L, Clarke SR, Baker DR. Factors associated with the likelihood of injury resulting from collisions between four-wheel drive vehicles and passenger cars. Accid Anal Prev 2003;35:677-81.

5. Bener A, Ghaffar A, Azab A, Sankaran-Kutty M, Toth F, Lovasz G. The impact of four-wheel drives on traffic disability and deaths compared to passenger cars. J Coll Physicians Surg Pak 2006;16:257-60.

6. Bener A, Al-Maadid M, Ozkan T, Al-Bast DA, Diyab KN, Lajunen T. The impact of four wheel drive on risky driver behaviors and road traffic accidents. Transp Res Part F Traffic Psychol Behav 2008;11:324-33.

7. Bener A Ozkan T, Lajunen T. The driver behaviour questionnaire in Arab Gulf Countries: Qatar and United Arab Emirates. Accid Anal Prev 2008;40:1411-7.

8. Bener A, Crundall D. Road traffic accidents in the United Arab Emirates compared to western countries. Adv Transp Stud 2005;6:5-12.

9. Ganos D, Crady S, Poortenga S, Hoffman G, Mann R. Trauma associated with three- and four-wheeled all terrain vehicles: Is the four-wheeler an unrecognized health hazard? Am Surg 1988;54:429-33.

10. Ballesteros MF, Dischinger PC, Langenberg P. Pedestrian injuries and vehicle type in Maryland, 1995-1999. Accid Anal Prev 2004;36:73-81.

11. Smyth TL, King MJ. Driver-vehicle interactions in 4WDs: A theoretical review. In Australasian Road Safety Research, Policing Education Conference 2006, 25 - 27 October 2006, Gold Coast, Queensland, Australia. Available from: http://eprints.qut.edu.au/6241/1/6241_1.pdf

12. Bener A, Zirie MA, Kim EJ, Al Buz R, Zaza M, Al-Nufal M, et al. Measuring Burden of Diseases in a Rapidly Developing Economy: State of Qatar. Glob J Health Sci 2013;5:134-44.

13. Lajunen T, Summala H. Driver experience, personality, and skill and safety motive dimensions in drivers' self-assessments. Pers Individ Dif 1995;19:307-18.

14. Åberg L, Rimmö PA. Dimensions of aberrant driver behaviour. Ergonomics 1998;41:39-56.

15. Warner HW, Ozkan T, Lajunen T, Tzmalouka G. Cross cultural comparison of drivers' tendency to commit different aberrant driving behaviours. Transp Res Part F Traffic Psychol Behav 2011;14:390-9.
16. Parker D, West R, Stradling S, Manstead AS. Behavioural characteristics and involvement in different types of traffic accident. Accid Anal Prev 1995;27:571-81.

17. Mesken J, Lajunen T, Summala H. Interpersonal violations, speeding violations and their relation to accident involvement in Finland. Ergonomics 2002;45:469-83.

18. Lajunen T, Parker D, Summala H. The Manchester Driver Behaviour Questionnaire: A cross-cultural study. Accid Anal Prev 2004;36:231-8.

19. Lawton R, Parker D, Stradling SG. Predicting road traffic accidents: The role of social deviance and violations. Br J Psychol 1997;88:249-62.

20. Özkan T, Lajunen T, Chliaoutakis J, Parker D, Summala H. Cross-cultural differences in driving behaviours: A comparison of six countries. Transp Res Part F Traffic Psychol Behav 2006;9:227-42.

21. Bener A, Lajunen T, Ozkan T, Haigney D. The effect of mobile phone use on driving style and driving skills. Int J Crashworthiness 2006;11:459-65.

22. Gras ME, Sullman MJ, Cunill M, Planes M, Aymerich M, Font-Mayolas S. Spanish drivers and their aberrant driving behaviours. Transp Res Part F Traffic Psychol Behav 2006;9:129-137

23. Lajunen T, Corry A, Summala H, Hartley L. Cross-cultural differences in Drivers' self-assessments of their perceptual-motor and safety skills: Australians and Finnish. Pers Individ Dif 1998;24:539-50.

24. Bener A, Alwash R. A perspective on motor vehicle crash injuries and speeding in the United Arab Emirates. Traffic Inj Prev 2002;3:61-4.

25. Ansari S, Akhdar F, Madoorah M, Mutaery K. Causes and effects of road traffic accidents in Saudi Arabia. Public Health 2000;114:37-9.

26. Parker D, Reason JT, Manstead AS, Stradling SG. Driving errors, driving violations and accident involvement. Ergonomics 1995;38:1036-48.

27. Bener A, Crundall D, Haigney D, Bensiali AK, Al-Falasi AS. Driving behaviour stress, error and violations on the road: A cross-cultural comparisons study. Adv Transp Stud 2007;12:5-14.

28. McKnight AJ, McKnight AS. Young novice drivers: Careless or clueless. Accid Anal Prev 2003;35:921-5.

29. Bener A, Crundall D. Road traffic accidents in the United Arab Emirates compared to western countries. Adv Transp Stud 2005;6:5-12.

30. Bener A, Crundall D. Effects of driver behaviour on accident involvement: The role of gender and driver behaviour in Road Traffic Crashes. Int J Crashworthiness 2008;13:331-6.

How to cite this article: Bener A, Razzak JA, Crundall D, Allen KA. The relationship between four-wheel drives and risky driving behaviours. Int J Med Public Health 2014;4:280-6.

Source of Support: Nil, Conflict of Interest: We have no financial interest to declare. 